\title{
Was there life before 1953?
}

\author{
James F. Crow
}

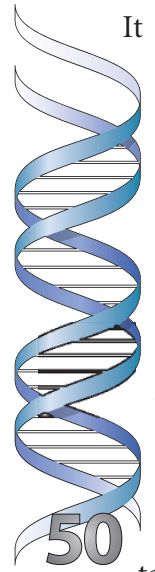

It has been fifty years since the Watson-Crick bombshell. Fifty years before that, in 1903, Walter Sutton ${ }^{1}$ noted the parallelism between chromosome behavior and Mendel's laws, thus identifying genes with chromosomes and marking the beginning of genetics as a science. The next half-century was one of great progress, but it was a different world from ours. My assignment is to contrast genetics before and after 1953. I am well qualified for this task; my genetics career started in the 1930s, so I belong to that fast-disappearing cohort who experienced the old ways.

Through a retrospectroscope, the pre-1953 years look barren indeed: no DNA sequencers, no PCR, no SNPs, no expression chips, no sequence databases, no computers, no central dogma, no reverse transcriptase, no code dictionary, no junk DNA, no antisense RNA, no RNAi, no molecular clock, no knockouts, no gene targeting, no evo-devo and so on and on.

The central puzzle, of course, was the gene. It seemed totally mysterious, completely out of the range of techniques of the time. There was no shortage of speculation, none of which was anywhere close to the eventual answer. In reviewing the 1932 International Genetics Congress, R.C. Cook ${ }^{2}$ wrote, "Oceans of words were spilled in formal and informal gatherings to discuss the vital question: 'What is the gene?' but that important entity is still elusive." Many thought we were not likely to know in our lifetime. Most geneticists simply worked on other problems. As one exam-
"Through a retrospectroscope, the pre-1953 years look barren indeed: no DNA sequencers, no PCR, no SNPs..."
New knowledge from new techniques. By far, the most important development is the insight brought about by molecular technology. Among the countless examples that exist, I have selected one. If not as shocking as Darwin's pronouncement, it has nevertheless drastically altered the way we look at evolution and species differences. Today, we take it for granted that differences between species, genera, families, even kingdoms, involve changes in the DNA. We see some genes conserved for hundreds of millions of years. Yet, before molecular technology, there was considerable doubt. Studies of evolutionary genetics were limited to species that could be crossed-genetic differences between mice and elephants were out of bounds.

Illustrative of the uncertainties at the time was a difference of opinion between A.H. Sturtevant and S.C. Harland. Sturtevant argued that mutants with the same phenotype in related species had mutations in homologous genes. Harland argued that these were often at different loci and carried this observation to its logical extreme 4 ". . organs such as the eye, which is common to all vertebrate animals, preserve their essential similarity in structure or function, though the genes responsible for the organ must have become wholly altered during the evolutionary process since there is no reason to suppose that homologous organs have anything genetically in common."

Actually, Sturtevant had the better argument. At least he showed where Harland was led astray ${ }^{4}$. Harland was studying cotton, an amphidiploid, so allelic mutants from different ancestral strains could reside in different chromosomes. The ple, evolutionary genetics was very popular, thanks to the enthusiasm and communicative skills of Th. Dobzhansky ${ }^{3}$.

Although the central focus was missing, geneticists still knew a great deal. A.H. Sturtevant had shown how to determine a gene's position on the chromosome and had constructed the first linkage map. (Both Sutton and Sturtevant made their discoveries while students.) The mutation rate could be enhanced by radiation and, in the late 1940s, by chemicals. Cytogenetics thrived in Drosophila and many plants. The main practical beneficiary was agriculture. Plant breeding was highly developed, with hybrid maize the greatest achievement. Polyploidy permitted fertile hybrids, of great value in horticulture. Thanks to Fisher and Wright, there was a predictive theory for animal and plant breeding and, along with this, a solid mathematical theory of population genetics and evolution.

There are endless contrasts, and some similarities, between then and now. I shall give examples of new knowledge made possible by molecular techniques, theories that have become prominent recently but might well have been found earlier, early research that later became useful because of new techniques and early incorrect ideas that were not straightened out until later. point is that, before molecular methods, such questions could only be debated, not answered. Now they can be studied experimentally; one can analyze the genetic differences between mice and elephants.

New knowledge versus early techniques. Here are two examples of phenomena that have recently been discovered but might have been found much earlier. One is imprinting. Why wasn't this discovered long ago? A frequent manifestation is difference in reciprocal crosses, which should have been easily observed. I suspect that one reason was a belief in the generality of results obtained from Drosophila and maize. Exceptions in less well understood organisms, like mice, got brushed aside. Of course, the proper analysis depends on molecular techniques, but the basic discovery might well have been made decades earlier.

A second example is evolution of cooperation and altruism. The late Bill Hamilton ${ }^{5}$, who dominated this field, did not need molecular techniques. The key explanatory idea, kin selection, was understood by both Haldane and Fisher, but neither saw fit to develop it. Sociobiology and evolutionary psychology might well have been active research areas in the 1930s. 


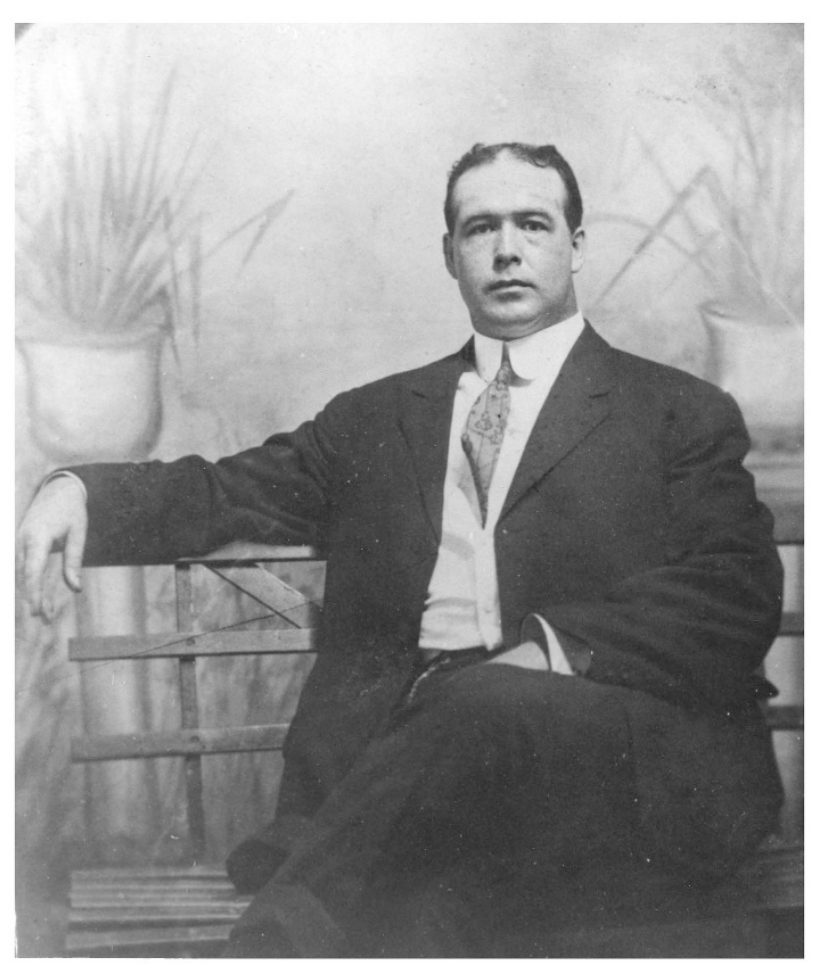

Walter Sutton as a medical student, circa 1905. After making his great discovery that established genetics as a science, he never completed graduate work but went on to a distinguished career in surgery ${ }^{13}$.

Early knowledge and new techniques. Here are two examples of work that was completed before the availability of molecular techniques and became important later. Motoo Kimura solved a number of problems in theoretical population genetics, particularly those involving stochastic processes. These included the probability of fixation of a new mutant and the time required for fixation. This theory turned out to be preadapted for later use when molecular evolution became quantitative ${ }^{6}$.

Another case is Newton Morton's ${ }^{7}$ development of lod scores to assess linkage. At the time of its development, the possible uses in human genetics were extremely limited. Now, with abundant markers, it has become standard. Practical results often have followed earlier mathematics, but these two examples are unusual in that the applications came within the lifetimes of their originators. Early incorrect ideas. Here is an example in which a wrong observation may have held up a field. C. B. Davenport ${ }^{8}$, who had some good ideas but now is regularly castigated for eugenic naiveté, thought that what was then called mongolism was due to trisomy. He managed to obtain some human chromosome material and sent it to T.S. Painter, then the leading human cytologist. Painter examined the chromosomes and could find nothing wrong. This finding was reported in a plenary lecture in the 1932 International Genetics Congress. I wonder if this observation discouraged others from looking for human chromosome anomalies?

A primary difference between those times and the present is the (relatively) lavish research support in recent times. Before World War II research funds were limited. Most geneticists did most of their own work. Some had graduate students and some had assistance with routine laboratory chores, but research teams were rare. Furthermore, equipment was limited, often only a microscope and a kitchen. Postdoctoral fellowships were few; most $\mathrm{PhDs}$ went directly to teaching positions (and in the depressed 1930s took any job they could get). Often research was grafted onto a busy teaching schedule. Data analysis was by hand or by noisy, slow calculators. No wonder results came much slower than they do now with our precision equipment, computer analysis and technical assistants.

The total number of geneticists was much smaller in the early days, as was the number of publications. It was possible to read all the papers published in the field, and a few, notably Sewall Wright, actually did this. Most of the active researchers knew each other. It was a simpler world.

By the mid-1940s it was clear that genetics was heading in a new direction. In the 1945 Pilgrim Trust Lecture, H.J. Muller ${ }^{9}$ wrote of "the coming chemical attack on the gene". The discovery of recombination in bacteria and viruses increased the resolving power of genetic analysis by orders of magnitude. At the same time, chemists were learning to deal with very large molecules. The attack on the gene now had much more powerful weapons. Yet, the Watson-Crick model came not from a forceful frontal attack, but by a clever end run.

In the early 1920s, Muller ${ }^{10}$ had told us what the gene has to do. It has to carry information, enormous amounts. It has to replicate itself with extraordinary precision. It has to make occasional mistakes-not surprising - but it has to replicate the mistakes, which is surprising. No wonder the Watson-Crick model caught on instantly, once it was understood. Its very structure shouted the mechanism for Muller's well known properties.

Another question immediately arises: what if Watson and Crick had not discovered the double helix? How long would the genetics world have remained in ignorance? According to Crick $^{11}$, probably not more than two or three years. Any of several people might have found the answer. Rosalind Franklin is a possibility, but she was emphasizing viruses. Maurice Wilkins was starting to work full-time on the DNA problem, using model-building along with his knowledge of crystallography. And, of course, there was Linus Pauling. Holt ${ }^{12}$, in reviewing a biography of Franklin, notes that if Pauling had been able to travel to London in 1951 he would probably have been shown the famous X-ray picture that gave Jim Watson the crucial hint. The greatest chemist of his time would surely have realized the significance and might have deduced the structure as quickly as Watson and Crick did. But Pauling was kept from traveling outside the United States because he had been accused of Communist sympathies. Is it possible that Watson and Crick owe their priority to Joe McCarthy? It's a thought too horrible to contemplate.

1. Sutton, W.S. Biol. Bull. 4, 231-251 (1903).

2. Cook, R.C. J. Hered. 23, 355-360 (1932).

3. Dobzhansky, T. Genetics and the Origin of Species (Columbia University Press, New York, 1937)

Sturtevant, A.H. Am. Sci. 36, 225-236 (1948)

5. Hamilton, W.D. Narrow Roads of Gene Land. Vol. 1 Evolution of Social Behavior (W.H. Freeman, New York, 1996).

6. Kimura, M. The Neutral Theory of Molecular Evolution (Cambridge Univ. Press, Cambridge, 1983).

7. Morton, N.E. Segregation and linkage. in Methodology of Human Genetics (ed. W. Burdette) 17-52 (Holden-Day, San Francisco, 1962)

8. Davenport, C.B. Proc. Sixth Int. Congr. Genet. 1, 135-140 (1932).

9. Muller, H.J. Proc. Roy. Soc. Lond. B Biol. Sci. 134,1-37 (1947).

10. Muller, H.J. Proc. Int. Cong. Plant Sci. 1, 897-921 (1929).

11. Crick, F. What Mad Pursuit (Basic Books, New York, 1988).

12. Holt, J. New Yorker, Oct 28, 102-108 (2002).

13. Crow, E.W. \& Crow, J.F. Genetics 160, 1-4 (2002). 